\title{
Setting priorities for humanitarian water, sanitation and hygiene research: a meeting report
}

\author{
Lauren D'Mello-Guyett ${ }^{1,10^{*}}$ (D), Travis Yates ${ }^{2}$, Andy Bastable ${ }^{3}$, Maysoon Dahab ${ }^{4,15}$, Claudio Deola ${ }^{5}$, Caetano Dorea ${ }^{6}$, \\ Robert Dreibelbis ${ }^{1}$, Timothy Grieve ${ }^{7}$, Thomas Handzel ${ }^{8}$, Anne Harmer ${ }^{4}$, Daniele Lantagne ${ }^{9}$, Peter Maes ${ }^{10}$, \\ Melissa Opryszko ${ }^{11}$, Sarah Palmer-Felgate ${ }^{4}$, Brian Reed ${ }^{12}$, Rafael Van Den Bergh ${ }^{13}$, Dominique Porteaud ${ }^{14}$ \\ and Oliver Cumming ${ }^{1}$
}

\begin{abstract}
Recent systematic reviews have highlighted a paucity of rigorous evidence to guide water, sanitation and hygiene (WASH) interventions in humanitarian crises. In June 2017, the Research for Health in Humanitarian Crises (R2HC) programme of Elrha, convened a meeting of representatives from international response agencies, research institutions and donor organisations active in the field of humanitarian WASH to identify research priorities, discuss challenges conducting research and to establish next steps. Topics including cholera transmission, menstrual hygiene management, and acute undernutrition were identified as research priorities. Several international response agencies have existing research programmes; however, a more cohesive and coordinated effort in the WASH sector would likely advance this field of research. This report shares the conclusions of that meeting and proposes a research agenda with the aim of strengthening humanitarian WASH policy and practice.
\end{abstract}

\section{Introduction}

Over the last decade, numerous scoping and systematic reviews have concluded that water, sanitation and hygiene (WASH) interventions in humanitarian crises can yield important health and social benefits for vulnerable affected populations [1-8]. However, all reviews found that: i) the current evidence base supporting humanitarian WASH interventions is limited; ii) policy and practice is often based on operational experience rather than independent evaluation; iii) that research to date has been dominated by studies of household or point-of-use (POU) water treatment with little research on the health or social impacts of community level water supply, sanitation, and hygiene interventions, or relative benefits of combined WASH interventions; and iv) evidence generation in humanitarian crises remains challenging and ad hoc.

\footnotetext{
* Correspondence: lauren.dmello-guyett@lshtm.ac.uk

'Department for Disease Control, Faculty of Infectious and Tropical Diseases, London School of Hygiene and Tropical Medicine, London, UK

${ }^{10}$ Water, Hygiene and Sanitation Unit, Medical Department, Médecins Sans

Frontières- Operational Center Brussels, Brussels, Belgium

Full list of author information is available at the end of the article
}

This paucity of evidence is reflected in guideline recommendations for humanitarian WASH programmes, such as the SPHERE standards [9], which are often not supported by rigorous, published evidence [9-15]. Although many response agencies routinely conduct programme evaluations, these are often not rigorous nor published; thereby limiting the uptake of findings. While this issue is common across the humanitarian sector, a systematic review of all public health interventions in humanitarian crises published in 2017, found that WASH interventions were supported by far fewer studies $(n=6)$ than other areas of public health [5].

In November 2016, during the 7th Emergency Environmental Health Forum (EEHF) in Kathmandu, Nepal [16], a group of leading response agencies, research institutions and donor organisations raised the idea of conducting a research priority-setting exercise for humanitarian WASH. In response, Elrha's Research for Health in Humanitarian Crises (R2HC) programme convened a two-day meeting (June 29-30th 2017) in Windsor, United Kingdom, with a group of international

(c) The Author(s). 2018 Open Access This article is distributed under the terms of the Creative Commons Attribution 4.0 International License (http://creativecommons.org/licenses/by/4.0/), which permits unrestricted use, distribution, and 
response agencies, research institutions, and donor organisations (Appendix A) [17].

The objective of the meeting was to identify key public health research priorities for humanitarian WASH research, informed by response agency, research institution and donor organisation perspectives, to strengthen policy and practice. Momentum for the meeting was supported by concurrent funding initiatives for health in humanitarian crises research such as the $\mathrm{R} 2 \mathrm{HC}$, the $\mathrm{Hu}-$ manitarian Innovation Fund (HIF) and the Humanitarian Evidence Programme (HEP). We have published this report of the meeting to expand the discussion beyond those who attended and to stimulate much-needed research interest and investment in the field of humanitarian WASH.

\section{Key conclusions}

The main outcomes of the meeting are presented below under three sub-headings: Research Priorities for Humanitarian WASH; Challenges with Conducting Research in Humanitarian Crises and Moving the Humanitarian WASH Research Agenda Forward.

\section{Research priorities for humanitarian WASH}

Ten key research priorities were identified by the attendees reflecting operational, research and donor perspectives:

1. WASH for the prevention and control of cholera

- To understand the relative importance of cholera transmission in the domestic and public domains and implications for effective humanitarian WASH responses

- To rigorously assess the effectiveness of conventional WASH interventions on cholera transmission in humanitarian crises

2. Menstrual hygiene management (MHM)

- To identify effective culturally appropriate MHM interventions for women and girls affected by humanitarian crises

- To identify social and cultural barriers to safe MHM interventions among women and girls affected by humanitarian crises

- To design and test strategies to integrate MHM interventions for different response phases (e.g. acute and post-acute phase)

3. Coordination of Oral Cholera Vaccine (OCV) and WASH interventions

- To evaluate the relative effectiveness of combined WASH and OCV versus OCV alone on cholera transmission in different settings and for different populations (e.g. in endemic versus epidemic settings)

- To design and test strategies for coordinating and targeting WASH and $\mathrm{OCV}$ interventions in different settings and for different populations (e.g. in endemic versus epidemic settings)

4. Strengthening the design and targeting of hygiene kits in WASH programmes

- To determine the most appropriate products to be included in hygiene kits in different responses phases (e.g. acute and post-acute phase)

- To understand the utilisation of hygiene kits and evaluate their effectiveness to control infectious disease outbreaks (e.g. cholera, Ebola, Hepatitis E)

5. WASH in moderate/severe acute malnutrition programmes

- To identify appropriate WASH interventions to include in programmes for management of child moderate acute malnutrition (MAM) and severe acute malnutrition (SAM) in humanitarian crises

- To evaluate the effect of combined WASH and MAM/SAM interventions on reduce relapse rates, duration of treatment and overall mortality among children in humanitarian crises

6. WASH-related enteric disease and transmission

- To ascertain aetiology of childhood diarrhoeal disease in humanitarian settings and other symptomatic and asymptomatic consequences of faecal oral diseases

- To assess dominant transmission routes for specific diarrhoeal diseases (e.g. cholera, Shigella, pathogenic E. coli) which present a high burden in given humanitarian crises

7. WASH for reproductive, maternal and neonatal health

- To design humanitarian WASH interventions that support safe delivery practices at home and in facilities

- To evaluate whether humanitarian WASH interventions at home and in facilities can improve maternal and neonatal health outcomes

8. Strengthening the hygiene component of humanitarian WASH programmes

- To understand the motivational drivers of sustained handwashing practices and maintenance of facilities in humanitarian crises

- To design and evaluate behaviour change interventions to increase handwashing with soap at key times in humanitarian crises

- To design and evaluate behaviour change interventions that improve the sustainability of other hygiene behaviours (e.g. personal and domestic hygiene) in populations affected by humanitarian crises 
9. Strengthening the sanitation component of humanitarian WASH programmes

- To design and evaluate behaviour change interventions to increase sanitation uptake in humanitarian crises

- To design and evaluate novel sanitation technologies for use in the acute phase of humanitarian crises

- To design and evaluate novel technologies and approaches to improve sanitation uptake among vulnerable populations, including people with disabilities and young children, in humanitarian crises

10. WASH as part of the effective transition between emergency and development

- To evaluate the impact of strategies for improved coordination amongst WASH response agencies and between WASH and health sectors on performance indicators

- To describe and evaluate current coordination mechanisms for transitionary handover of WASH services from response agencies to national government and/or other development actors

\section{Challenges with conducting research in humanitarian crises} Participants shared their current research programmes and related how this work had been initiated and developed. A wide range of research activities were shared but these efforts were largely independent and uncoordinated, with topics reflecting individual organisation's mandates rather than broader strategic or sectoral areas of interest or concern. Participants remarked that it might not be feasible or even desirable for all agencies to adhere to a common research agenda due to organisational priorities, although a common agenda might help to guide future research activities, donor investments and research collaborations.

Humanitarian crises, by definition, provide a challenging context for undertaking research. Most often in crises, affected populations have acute needs, response agencies operate under severe logistical constraints, and the sociopolitical environment is often unstable. Resources and opportunities for research in these settings are limited, particularly more intensive research involving differing standards of care and experimental interventions. Organisations undertaking research need to plan in advance, often significantly ahead of an actual emergency yet remain pragmatic and adaptive when research is executed.

\section{Participants identified a set of key barriers to conducting research}

- Difficult to secure ethical approval rapidly
- Limited investment in research and resources not readily available

- Challenges in reconciling interests and needs of response agencies and research institutions with regard to what constitutes "sufficient rigour"

- Conflicting timelines of response efforts and research protocols

- Lack of staff trained in research methods within humanitarian organisations

- Weak connections between research, and policy and practice functions within agencies

- Limited public data sharing, and publication of internal evaluations

Moving the humanitarian WASH research agenda forward There was consensus on the importance of research and the need to strengthen the evidence base for these interventions but also a recognition that dedicated efforts are needed to support uptake of findings within and across sector agencies.

Many of the response agencies present had specific programmes to train staff and increase research outputs. Examples included the Centers for Disease Control and Prevention (CDC) "Epidemiology for WASH" training programme, the "Using evidence for WASH policy and practice" course run between UNICEF and the London School of Hygiene and Tropical Medicine (LSHTM) and other WASH-specific training programmes run internationally [18], the Médecins Sans Frontières (MSF) operational research trainings "SORT-IT" [19] and recent "WASH-IT" spin off, and dedicated operational research units such as those within Action Contre La Faim (ACF), MSF and among other agencies. There were also examples of academic-humanitarian partnerships with universities in the U.S., UK, Europe, Africa and Asia conducting collaborative research with response agencies; often involving both Masters (MSc) and Doctoral (PhD) students.

A notable challenge remains in establishing and maintaining connections from research findings and teams operating in-country. The group recognised that research uptake needs careful consideration in dedicated training programmes in order to build local capacity for research and evaluation and as an advocacy tool across the humanitarian WASH, health, nutrition and shelter sectors. Revisions to guidelines and manuals needs to be evidence-based with Specific, Measurable, Achievable, Relevant and Time-Related (SMART) indicators to aid monitoring and evaluation. Participants noted that a cultural shift is required within most organisations to carry out and incorporate research within their programmes or to build linkages with agencies who have that technical expertise. 
Engagement of all members of the Global WASH Cluster was flagged as important to establish a representative view and ensure the involvement of the broader group of those involved in the humanitarian WASH response. This meeting was intended to gauge interest and undertake initial discussions on the direction for future WASH in humanitarian crises research. The group made two commitments towards sustaining momentum on this agenda:

\section{Engage with the wider humanitarian WASH} community: A survey will be undertaken amongst response agencies with active WASH programmes to map the current and future research activities and to identify research priorities. Full engagement with field staff as well as international managers is necessary to foster buy-in and identify relevant research objectives. Immediate opportunities to broaden the dialogue on this agenda are the 2018, and ongoing editions of, the Emergency Environmental Health Forum (EEHF), the Water Engineering Development Centre (WEDC), and the University of North Carolina (UNC) Water and Health conferences.

2. Knowledge Sharing: Greater efforts will be made to disseminate publications, advertise training opportunities, publicise relevant calls for proposals and share information on ongoing research activities. Identified opportunities for this include the nascent Technical Working Group (TWiG) within the Global WASH Cluster and the use of existing repositories for published and nonpublished research outputs including those within the Global WASH Cluster platform [20] and others $[21,22]$.

\section{Conclusion}

The scale, duration and complexity of humanitarian crises is increasing [23], with a growing population of highly vulnerable people. Responding to these crises requires strong evidence on what works to guide more effective and efficient investment and to achieve better health and social outcomes. Addressing the humanitarian WASH evidence gap is a joint concern of the response agencies, research institutions and donor organisations who attended this meeting. A greater commitment within the humanitarian WASH sector is needed to generate this evidence and an increased investment of resources to achieve this. Our meeting provided a platform for the leading international response agencies, research institutions and donor organisations active in the humanitarian WASH sector to undertake a participatory research priority setting exercise. We hope that sharing the conclusions from this meeting will support a broader and ongoing discussion in the humanitarian WASH sector as to how we can strengthen the evidence base to support the delivery of better WASH interventions for vulnerable crisis-affected populations.

\section{Appendix A \\ Organisations represented}

- Action Contre la Faim (ACF)

- Centers for Disease Control and Prevention (CDC)

- Elrha

- Global WASH Cluster (GWC)

- London School of Hygiene and Tropical Medicine (LSHTM)

- Médecins Sans Frontières (MSF)

- Office of U.S Foreign Disaster Assistance (OFDA), United States Agency for International Development (USAID)

- Oxfam

- Save the Children

- Tufts University

- UNICEF

- University of Victoria

- Water, Engineering and Development Centre (WEDC), Loughborough University

Abbreviations

ACF: Action Contre la Faim; CDC: Centers for Disease Control and Prevention; DFID: Department for International Development; EEHF: Emergency Environmental Health Forum; HEP: Humanitarian Evidence Programme; HIF: Humanitarian Innovation Fund; LSHTM: London School of Hygiene and Tropical Medicine; MAM: Moderate Acute Malnutrition; MHM: Menstrual Hygiene Management; MSF: Médecins Sans Frontières; OCV: Oral Cholera Vaccine; POU: Point-Of-Use water treatment; R2HC: Research for Health in Humanitarian Crises; SAM: Severe Acute Malnutrition; SMART: Specific, Measurable, Achievable, Relevant and Time-Related; TWiG: Technical Working Group; UNC: University of North Carolina; WASH: Water, Sanitation and Hygiene; WEDC: Water, Development and Engineering Centre

\section{Acknowledgements}

We would like to thank the many members of our respective organisations and colleagues beyond these organisations who, although they did not participate in the meeting, helped inform our discussions through their ongoing work.

\section{Funding}

The meeting was supported by Elrha's Research for Health in Humanitarian Crises (R2HC) programme which is jointly funded by the Department for International Development (DFID) and the Wellcome Trust.

Availability of data and materials

Not applicable.

Author's contributions

LDG, TY, RD and OC prepared the first draft of the manuscript. All authors contributed to the final manuscript. All authors gave final approval of the manuscript.

Ethics approval and consent to participate

Not applicable.

Consent for publication

Not applicable. 


\section{Competing interests}

The authors declare that they have no competing interests.

\section{Publisher's Note}

Springer Nature remains neutral with regard to jurisdictional claims in published maps and institutional affiliations.

\section{Author details}

'Department for Disease Control, Faculty of Infectious and Tropical Diseases, London School of Hygiene and Tropical Medicine, London, UK.

${ }^{2}$ Independent Consultant, Boston, MA, USA. ${ }^{3}$ Oxfam International, Oxford, UK ${ }^{4}$ Elrha, London, UK. ${ }^{5}$ Save the Children UK, London, UK. ${ }^{6}$ Department of Civil Engineering, University of Victoria, Victoria, British Columbia, Canada. ${ }^{7}$ UNICEF, New York, USA. ${ }^{8}$ Emergency Response and Recovery Branch, Center for Global Health, Division of Global Health Protection, Centers for Disease Control and Prevention, Atlanta, GA, USA. ${ }^{9}$ Department of Civil and Environmental Engineering, Tufts University, Boston, MA, USA. ${ }^{10}$ Water, Hygiene and Sanitation Unit, Medical Department, Médecins Sans FrontièresOperational Center Brussels, Brussels, Belgium. ${ }^{11}$ Office of U.S. Foreign Disaster Assistance, United States Agency for International Development, Washington D.C., USA. ${ }^{12}$ Water, Engineering and Development Centre, Loughborough University, Loughboroughg, UK. ${ }^{13}$ Operational Research Unit (LuxOR), Médecins Sans Frontières -Luxembourg, Luxembourg, Luxembourg. ${ }^{14}$ Global WASH Cluster, UNICEF, Geneva, Switzerland. ${ }^{15}$ Independent Consultant, London, UK.

Received: 7 February 2018 Accepted: 2 April 2018

Published online: 15 June 2018

\section{References}

1. Parkinson J. A review of the evidence base for WASH interventions in emergency responses/ relief operations: discussion document. ATKINS, 2009.

2. Brown J, Cavill S, Cumming O, Jeandron A. Water, sanitation, and hygiene in emergencies: summary review and recommendations for further research. Waterlines. 2012;31(1-2):11-29.

3. Bastable A, Russell L. Gap analysis in emergency water, sanitation and hygiene promotion. London: Humanitarian Innovation Fund; 2013.

4. Ramesh A, Blanchet K, Ensink JH, Roberts B. Evidence on the effectiveness of water, sanitation, and hygiene (WASH) interventions on health outcomes in humanitarian crises: a systematic review. PLoS One. 2015;10(9):e0124688.

5. Blanchet K, Ramesh A, Frison S, Warren E, Hossain M, Smith J, et al. Evidence on public health interventions in humanitarian crises. Lancet. 2017;390: 2287-96.

6. Yates T, Allen J, Joseph M, Lantagne D. Short-term WASH interventions in emergency response: a systematic review. London: International Initiative for Impact Evaluation (3ie); 2017.

7. Yates J, Allen J, Joseph M, Lantagne D. WASH interventions in disease outbreak response. Oxford: Humanitarian Evidence Programme: Oxfam GB; 2017.

8. Taylor DL, Kahawita TM, Cairncross S, Ensink JH. The impact of water, sanitation and hygiene interventions to control cholera: a systematic review. PLoS One. 2015:10(8):e0135676.

9. SPHERE. The Sphere project: humanitarian charter and minimum standards in humanitarian response. 3rd edition ed. Rugby: Practical Action Publishing; 2011.

10. Blanchet K, Frison S, Smith J. Review of the evidence supporting the SPHERE standards. London: R2HC- Elrha; 2017.

11. Blanchet K, Frison S. Survey on the knowledge, use, structure and content of the SPHERE handbook. London: R2HC- Elrha; 2017.

12. Van Dyke M, Waldman R. The Sphere project evaluation. New York: Mailman School of Public Health, Colombia University; 2004.

13. Griekspoor A, Collins S. Raising standards in emergency relief: how useful are Sphere minimum standards for humanitarian assistance? BMJ. 2001; 323(7315):740-2.

14. Ratnayake R, Degomme O, Roberts B, Spiegel P. Conflict and health: seven years of advancing science in humanitarian crises. Confl Heal. 2014:8:7.

15. Clarke M, Allen C, Archer F, Wong D, Eriksson A, Jyotsna P. What evidence is available and what is required, in humanitarian assistance? 3ie scoping paper 1. New Delhi: International Initiative for Impact Evaluation (3ie); 2014.

16. 7th Emergency Environmental Health Forum Report. Kathmandu. Nepal: SHARE Research Consortium; 2016.
17. D'Mello-Guyett L, Yates T. WASH in emergencies research prioritsation meeting: briefing paper. London: R2HC- Elrha; 2017.

18. Dorea C. Landscape of WASH-relevant training for humanitarian emergencies. PLoS Curr. 2015. p. 7. https://doi.org/10.1371/currents.dis. a0351bdc63f477245858caa7638e8525.

19. Zachariah R, Ford N, Maher D, Bissell K, Van den Bergh R, van den Boogaard $W$, et al. Is operational research delivering the goods? The journey to success in low-income countries. Lancet Infect Dis. 2012;12(5):415-21.

20. Global WASH Cluster. Available from: http://washcluster.net/. Accessed 31 Jan 2018.

21. MSF. Field Repository. Available from: http://fieldresearch.msf.org/msf/. Accessed 31 Jan 2018

22. WEDC. WEDC Publications for sustainable development and emergency relief. Available from: http://www.lboro.ac.uk/research/wedc/resources/pubs/. Accessed 31 Jan 2018.

23. Latimer C, Swithern S. Global humanitarian assistance report. Bristol: Development Initiatives; 2017.

\section{Ready to submit your research? Choose BMC and benefit from:}

- fast, convenient online submission

- thorough peer review by experienced researchers in your field

- rapid publication on acceptance

- support for research data, including large and complex data types

- gold Open Access which fosters wider collaboration and increased citations

- maximum visibility for your research: over $100 \mathrm{M}$ website views per year

At BMC, research is always in progress.

Learn more biomedcentral.com/submissions 